\title{
锂一空气电池性能的影响因素及研究进展
}

\author{
顾大明 $*$, $a$ 张传明 ${ }^{a}$ 顾硕 ${ }^{b}$ 张音 ${ }^{a}$ 王余 ${ }^{a}$ 强亮生 ${ }^{a}$ \\ ${ }^{a}$ 哈尔滨工业大学化学系 哈尔滨 中国 150001) \\ ( ${ }^{b}$ 乔治华盛顿大学电子与计算机工程系 华盛顿 美国 20052)
}

\begin{abstract}
摘要 锂-空气电池理论比能量高达 $3622 \mathrm{Wh} \cdot \mathrm{kg}^{-1}$ (设阴极还原产物为 $\mathrm{Li}_{2} \mathrm{O}_{2}$ ), 远超过目前已有的任何电池, 有希望成 为新一代的二次电池. 然而, 目前其实用化研究还处于探索阶段, 在其商用之前还有许多工作要做. 对影响锂一空气电 池性能的因素以及近期的研究进展进行综述，总结了阴极材料的组成和微观结构、电解质的种类及组成、阴极疏水膜、 电池结构设计、电池的组装及充、放电的工艺过程等对电池比能量、比容量以及循环性能等的影响，概述了锂-空气电 池的表征手段, 并对锂-空气电池的应用前景进行了展望.
\end{abstract}

关键词 锂-空气电池; 研究进展; 影响因素; 阴极材料; 电解质

\section{Research Progress and the Limiting Factors that Affect Performance of the Lithium Air Batteries}

\author{
Gu, Daming*,a \\ Zhang, Chuanming ${ }^{a}$ \\ $\mathrm{Gu}, \mathrm{Shuo}^{b}$ \\ Zhang, Yin ${ }^{a}$ \\ Wang, $\mathrm{Yu}^{a}$ \\ Qiang, Liangsheng ${ }^{a}$ \\ ( ${ }^{a}$ Department of Chemistry, Harbin Institute of Technology, Harbin 150001, China) \\ ( ${ }^{b}$ Department of Electrical and Computer Engineering, The George Washington University, Washington, DC, 20052, USA)
}

\begin{abstract}
Lithium air battery has attracted extensive attention due to its potential in achieving much higher practical specific energy than existing batteries, and it may become one of the most promising next generation battery technologies. Lithium air battery has the compelling advantage of theoretical specific energy, i.e. $3622 \mathrm{Wh} \bullet \mathrm{kg}^{-1}$ (assuming $\mathrm{Li}_{2} \mathrm{O}_{2}$ is the product), which is attributed to the use of a lithium metal anode and the ready availability of the cathode oxidant, i.e. oxygen, from the surrounding air. Other advantages include stable potentials, high safety, low cost, friendly to environment. However, before Lithium air batteries can be commercialized, the following challenges still need to be overcome: optimization of the cathode materials structure and the electrolyte composition, enhancement of the actual discharge special capacity, and improvement of the cycle performance and elucidating the reaction mechanism that occurs during charge and discharge. In this paper, we presented the current research progress and the limiting factors that affect performance of the batteries, such as microcomposition and microstructure of the cathode materials, constitution of the electrolytes, oxygen selective membranes, the structure design for the lithium air batteries, charge and discharge mechanism; compared lithium air battery with other advanced batteries, i.e. lithium air battery, lithium ion battery, lead-acid battery, nickel-hydride battery and fuel cells electrochemical properties, such as specific capacity, specific energy, specific power and open circuit voltage; summarized the effect of the composition and structure of the cathode materials on its performance; discussed the merits and demerits of aqueous electrolyte, non-aqueous electrolyte and dual-electrolyte for Li-air batteries; analyzed the effect of solubility coefficient, conductivity and viscosity of various components non-aqueous electrolytes, established the heterogeneous reaction model of cathode in organic electrolyte and aqueous electrolyte and reviewed state-of-the-art characterization techniques of the materials for lithium air batteries and the application prospect of lithium air battery.
\end{abstract}

Keywords lithium air batteries; research progress; limiting factors; cathode materials; electrolytes

\section{1 引言}

近年来, 随着经济的快速发展, 全球能源危机日趋 严重, 生态环境日益恶化, 开发清洁、可再生能源已成 为当务之急, 人类必须正确把握经济增长 (Economic Growth), 环境保护(Environmental Protection)和能源供
给(Energy supply) “三 E” 之间的平衡关系，因此，大力 研究与开发高能量密度的电源体系及材料势在必行. 近 年来，人们将目光投向风能、太阳能、潮汐能等绿色可 再生能源, 然而, 这些能源的利用具有随机性和可变性, 难以控制，且存储运输很不方便. 若能开发出高效清洁 的储能技术并将这些能源加以利用，将有望解决人类目

\footnotetext{
* E-mail: gudaming@126.com

Received May 24, 2012; published September 11, 2012.

Supporting information for this article is available free of charge via the Internet at http://sioc-journal.cn.

Project supported by the Outstanding Subject Leaders special Foundation of Harbin, China (No. 2012RFXXG99).

项目受哈尔滨市优秀学科带头人专项资金(No. 2012RFXXG99)资助.
} 
前面临的环境污染和能源危机问题.

二次电池作为一种能量转化与储存装置, 在全球经 济可持续发展的进程中占有重要地位, 目前正向比能量 更高、更好安全、对环境更加友好的方向发展. 几种目 前正在开发或已商品化电池的相关数据如表 1 所示, 其 中锂-空气电池各种优异的性能受到了广泛的关注, 当 使用有机电解质且设 $\mathrm{O}_{2}$ 在阴极还原为 $\mathrm{Li}_{2} \mathrm{O}_{2}$ 时, 锂一空 气电池的理论比能量为 $3622 \mathrm{Wh} \bullet \mathrm{kg}^{-1}$, 高于氢氧燃料电 池和直接甲醇然料电池, 是锂离子电池的 6 9 倍, 是锌 空气电池理论比能量 $\left(1083 \mathrm{Wh} \cdot \mathrm{kg}^{-1}\right)$ 的近 3 倍, 更是远 高于镍氢电池和铅酸电池(表 1 ), 且对环境更加友好, 价 格低廉, 无疑具有广阔的应用潜力, 有望成为新一代的 二次电池.

锂-空气电池工作原理如图 1 所示.

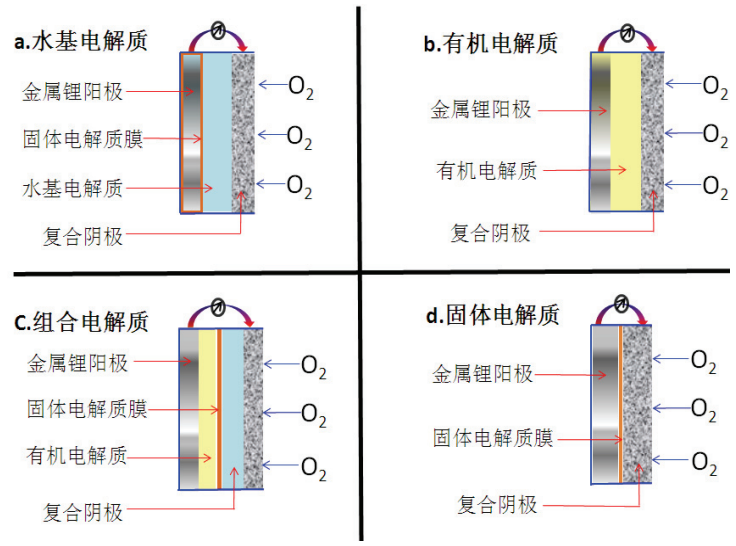

图 1 使用不同电解质时锂-空气电池结构示意图

Figure 1 Schematic of lithium air batteries with different electrolytes

\section{2 锂-空气电池的反应原理}

其电池反应取决于电解质的种类. (阴极)使用水基 电解质时(图 1a, 1c), 电化学反应式如 Eqs. 1 3.
阴极反应 1: $\mathrm{O}_{2}+2 \mathrm{H}_{2} \mathrm{O}+4 \mathrm{e}^{-} \rightarrow 4 \mathrm{OH}^{-}$

阳极反应: $\mathrm{Li} \rightarrow \mathrm{Li}^{+}+\mathrm{e}^{-}$

电池反应 1: $4 \mathrm{Li}+\mathrm{O}_{2}+2 \mathrm{H}_{2} \mathrm{O} \rightarrow 4 \mathrm{Li}^{+}+4 \mathrm{OH}^{-}$

$$
\left(E^{\ominus}=3.45 \mathrm{~V}\right)
$$

电池使用有机电解液或固体电解质时(图 1b, 1d), 化学反应式如 Eqs. $4 \sim 8$.

阴极反应 2: $\mathrm{O}_{2}+2 \mathrm{e}^{-}+2 \mathrm{Li}^{+} \rightarrow \mathrm{Li}_{2} \mathrm{O}_{2}$

阴极反应 3: $\mathrm{O}_{2}+4 \mathrm{e}^{-}+4 \mathrm{Li}^{+} \rightarrow 2 \mathrm{Li}_{2} \mathrm{O}$

阳极反应: $\mathrm{Li}^{+}+\mathrm{e}^{-} \rightarrow \mathrm{Li}$

电池反应 2: $2 \mathrm{Li}+\mathrm{O}_{2} \rightarrow \mathrm{Li}_{2} \mathrm{O}_{2}\left(E^{\Theta}=2.959 \mathrm{~V}\right)^{[1]}$

电池反应 3: $4 \mathrm{Li}+\mathrm{O}_{2} \rightarrow 2 \mathrm{Li}_{2} \mathrm{O}\left(E^{\Theta}=2.913 \mathrm{~V}\right)^{[1]}$

\section{3 锂-空气电池性能的影响因素及研究进展}

虽然锂一空气电池具有诱人的应用前景，但现阶段 其实际比能量还较低、循环性能还很不理想, 影响电池 性能的因素也很多，如：阴极材料的组成和微观结构、 电解质的种类及组成、阴极疏水膜、电池结构设计、放 电深度等. 目前锂-空气电池实用化研究还处于探索阶 段, 本文综述了锂-空气电池的主要影响因素以及研究 进展.

\section{1 阴极材料的组成和微观结构的影响}

\subsection{1阴极材料的组成的影响}

目前研究的阴极材料主要有碳载“金属”、碳载“金 属氧化物” 和碳载“金属/金属氧化物” 等.

(1)碳载“金属”催化剂: 2010 年，剑桥大学 $\mathrm{Lu}$ 等 ${ }^{[2,3]}$ 分别利用碳负载贵金属 $\mathrm{Au}, \mathrm{Pt}$ 及 Pt-Au 合金纳米粒子制 备阴极材料、组装锂-空气电池, 实验结果显示: 用 $\mathrm{Pt} /$ 碳、 $\mathrm{Au} /$ 碳和 Pt-Au/碳等催化剂做阴极材料时，放电比容 量分别为 780,1300 和 $1500 \mathrm{mAh} \cdot \mathrm{g}^{-1}$. 其中以 $\mathrm{Pt}-\mathrm{Au} /$ 碳

表 1 几种二次电池及燃料电池的相关电化学数据 ${ }^{a}$

Table 1 Several secondary batteries and fuel cells related electrochemical data ${ }^{a}$

\begin{tabular}{|c|c|c|c|c|c|}
\hline & 铅酸电池 & 镍氢电池 & 锂离子电池 & 锂-空气电池(有机电解质) & 氢氧燃料电池及直接甲醇燃料电池 \\
\hline 阳极 & $\mathrm{Pb} 259$ & $\mathrm{LaNi}_{5} 372$ & $\mathrm{C}_{6} 372$ & Li 3861 & $\begin{array}{l}\mathrm{H}_{2} \rightarrow 2 \mathrm{H}^{+}+2 \mathrm{e}^{-} 6647 \\
\mathrm{CH}_{3} \mathrm{OH}+\mathrm{H}_{2} \mathrm{O} \rightarrow \mathrm{CO}_{2}+6 \mathrm{H}^{+}+6 \mathrm{e}^{-} 5019\end{array}$ \\
\hline $\begin{array}{l}\text { 理论比容量/ } \\
\left(\mathrm{mAh} \cdot \mathrm{kg}^{-1}\right)\end{array}$ & $\mathrm{PbO}_{2} 224$ & $\mathrm{Ni}(\mathrm{OH})_{2} 289$ & $\begin{array}{l}\mathrm{LiMn}_{2} \mathrm{O}_{4} 148 \\
\mathrm{LiFePO}_{4} 170 \\
\mathrm{LiCoO}_{2} 274\end{array}$ & $\begin{array}{l}(1 / 2) \mathrm{O}_{2} \rightarrow \mathrm{O}^{2-} 3350 \\
\mathrm{O}_{2} \rightarrow \mathrm{O}_{2}^{2-} \quad 1675\end{array}$ & $(1 / 2) \mathrm{O}_{2} \rightarrow \mathrm{O}^{2-} 3350$ \\
\hline $\begin{array}{l}\text { 电池理论 } \\
\text { 电动势 } / \mathrm{V}\end{array}$ & 2.044 & 1.319 & - & $\begin{array}{l}(1 / 2) \mathrm{O}_{2} \rightarrow \mathrm{O}^{2-} 2.913 \\
\mathrm{O}_{2} \rightarrow \mathrm{O}_{2}^{2-} 2.959\end{array}$ & $\begin{array}{l}\text { 氢氧燃料电池 } 1.229 \\
\text { 甲醇燃料电池 } 1.213\end{array}$ \\
\hline 理论比能量/(Wh・ $\left.\mathrm{kg}^{-1}\right)$ & 170 & 215 & $\begin{array}{l}\mathrm{C}_{6} / \mathrm{LiFePO}_{4} 385 \\
\mathrm{C}_{6} / \mathrm{LiMn}_{2} \mathrm{O}_{4} 392 \\
\mathrm{C}_{6} / \mathrm{LiCoO}_{2} 568\end{array}$ & $\begin{array}{l}(1 / 2) \mathrm{O}_{2} \rightarrow \mathrm{O}^{2-} 5203 \\
\mathrm{O}_{2} \rightarrow \mathrm{O}_{2}^{2-} 3622 \\
\text { 不考虑氧气 } 11400\end{array}$ & $\begin{array}{l}\mathrm{H}_{2} \text { 阳极 } 1937 \\
\mathrm{CH}_{3} \mathrm{OH} \text { 阳极 } 3484\end{array}$ \\
\hline 开路电压/V & 2.0 & 1.2 & $3.3 \sim 3.7$ & $2.2 \sim 2.8$ & $0.4 \sim 1.1$ \\
\hline 实际比能量/(Wh・kg $\left.{ }^{-1}\right)$ & $30 \sim 50$ & $35 \sim 70$ & $90 \sim 330$ & $850 \sim 3800$ & $780 \sim 3100$ \\
\hline 实际比功率/(W•kg $\left.{ }^{-1}\right)$ & $10 \sim 50$ & $56 \sim 100$ & $80 \sim 480$ & $280 \sim 840$ & $56 \sim 190$ \\
\hline
\end{tabular}

理论比容量及理论比能量值源于计算, 理论电动势源于化学用表或论文, 标称值或实际值源于产品说明、文献或笔者的实验数据. 
做催化剂的电池的放电电压始终比纯碳阴极电池高 $0.15 \sim 0.36 \mathrm{~V}$; 且充电过程中平均充电电压仅为 $3.6 \mathrm{~V}$, 远低于纯碳阴极电池 $(4.5 \mathrm{~V})$. 实验数据表明, Pt-Au/碳阴 极材料具有双功能催化活性, 既能减小放电过电位、提 高放电平台, 又能减小充电过电位、降低充电电压.

(2)碳载 “金属氧化物” 催化剂: 2006 年始, 英国圣 安德鲁斯大学 Bruce 课题组 ${ }^{[4,5]}$ 对锂-空气电池反应的可 逆性和多种金属氧化物催化剂的性能进行了研究, 认为 当放电产物为 $\mathrm{Li}_{2} \mathrm{O}_{2}$ 时, 电池反应具有可逆性. 在无催 化剂的情况下充电时, $\mathrm{Li}_{2} \mathrm{O}_{2}$ 的分解电压高达 $4.8 \mathrm{~V}$, 加 入锰氧化物催化剂后分解电压降低至 $4.3 \mathrm{~V}$. 首次放电 比容量为 $1000 \mathrm{mAh} \cdot \mathrm{g}^{-1}$ (碳)、电池循环 50 次以后, 容量 保持率为 $60 \%$, 虽其循环性能欠佳, 但作者认为经过改 进, 锂一空气电池有望成为新一代二次电池. 2007 年, Bruce 等 $^{[5]}$ 继续研究了多种金属氧化物作催化剂对电池 比容量及循环性能的影响, 结果表明: $\mathrm{NiO}, \mathrm{Fe}_{2} \mathrm{O}_{3}$, $\mathrm{Li}_{0.8} \mathrm{Sr}_{0.2} \mathrm{MnO}_{3}, \mathrm{CuO}, \mathrm{CoFe}_{2} \mathrm{O}_{4}$ 的催化活性均不理想, 而 $\mathrm{Co}_{3} \mathrm{O}_{4}$ 作催化剂时电池的充电电压降至 $4 \mathrm{~V}$, 首次放电 比容量达到 $2000 \mathrm{mAh} \cdot \mathrm{g}^{-1}$ (碳), 且具有良好的容量保持 率. 2008 年 Bruce 等 ${ }^{[6]}$ 又用 $\alpha-\mathrm{MnO}_{2}$ 纳米线、 $\alpha-\mathrm{MnO}_{2}$ 粗 颗粒、 $\beta-\mathrm{MnO}_{2}$ 纳米线作催化剂, 实验结果如表 2 所示.

表 $2 \mathrm{MnO}_{2}$ 晶型与形貌的不同对电池放电比容量的影响(放电电流为 $70 \mathrm{~mA} \cdot \mathrm{g}^{-1}$ )

Table 2 Specific capacity are compared with different crystal morphology of $\mathrm{MnO}_{2}$ at same cycling rate of $70 \mathrm{~mA} \cdot \mathrm{g}^{-1}$

\begin{tabular}{ccc}
\hline 催化剂 & $\begin{array}{c}\text { 初始放电比容量/ } \\
\left(\mathrm{mAh} \cdot \mathrm{g}^{-1}\right) \text { (碳) }\end{array}$ & $\begin{array}{c}\text { 循环 } 10 \text { 次以后比容量/ } \\
\left(\mathrm{mAh} \cdot \mathrm{g}^{-1}\right) \text { (碳) }\end{array}$ \\
\hline$\alpha-\mathrm{MnO}_{2}$ 纳米线 & 3000 & 1500 \\
$\alpha-\mathrm{MnO}_{2}$ 粗颗粒 & 1500 & 650 \\
$\beta-\mathrm{MnO}_{2}$ 纳米线 & 2400 & 50 \\
\hline
\end{tabular}

表 2 中数据说明, 催化剂的晶型及微观形貌对其催 化效果具有很大的影响.

2007 年, 美国康涅狄格州大学 Crisostomo 等 ${ }^{[7]}$ 合成 了碱式氧化锰 $(\mathrm{MnOOH})$, 并将其作为锂一空气电池的阴 极催化剂, 实验结果表明: 与未加 $\mathrm{MnOOH}$ 相比, 放电 比容量提高了 $38 \%$, 达到 $2200 \mathrm{mAh} \cdot \mathrm{g}^{-1}$ (碳).

2010 年, 美国西北国家实验室 Xiao 等 ${ }^{[8,9]}$ 用 3 种嵌 锂材料 $\left(\mathrm{MnO}_{2}, \mathrm{~V}_{2} \mathrm{O}_{5}, \mathrm{CF}_{x(x=1.0 \sim 1.15)}\right)$ 与 $\mathrm{KB}$ (科琴炭黑)复合 分别制备了空气阴极. 实验结果表明: 阴极材料中仅含 $\mathrm{KB}$ 时, 放电比容量为 $400 \mathrm{mAh} \cdot \mathrm{g}^{-1}$ (碳十催化剂); 其中 $\mathrm{MnO}_{2}$ 的加入对 $\mathrm{KB}$ 阴极的性能影响不大; $\mathrm{V}_{2} \mathrm{O}_{5} / \mathrm{KB}$ 复合 阴极在电流密度为 $0.1 \mathrm{~mA} \cdot \mathrm{cm}^{-2}$ 时放电比容量达到了 $800 \mathrm{mAh} \cdot \mathrm{g}^{-1}$ (碳十催化剂); 在相同的电流密度下, 用 $\mathrm{CF}_{x} / \mathrm{KB}$ 作阴极材料时, 放电比容量达到了 $950 \mathrm{mAh}$ $\mathrm{g}^{-1}$ (碳+催化剂). 由此可见, $\mathrm{CF}_{x} / \mathrm{KB}$ 的催化活性最好, 原因可能是其微观结构中含有足够的大孔结构, 因而有 效缓解了放电产物堵塞气孔道的问题.

2010 年, 英国 Cheng 等 ${ }^{[10]}$ 将锰氧化物催化剂直接
涂在碳纸上，通过纳米技术制成一种具有中孔结构的纳 米锰氧化物催化剂, 放电比容量达到 $4750 \mathrm{mAh} \cdot \mathrm{g}^{-1}$ (碳), 这个数据高于用 $\mathrm{EMD}$ (电解二氧化锰)作催化剂时的放 电比容量 $4000 \mathrm{mAh} \cdot \mathrm{g}^{-1}$ (碳).

2011 年, 佛罗里达州立大学 Zhang 课题组 ${ }^{[11]}$ 制备了 “ $\alpha-\mathrm{MnO}_{2}$ /碳纳米管/碳纳米纤维” 复合空气阴极, 研究发 现 $\mathrm{MnO}_{2}$ 的加入没有改变其首次放电比容量, 但大大提 高了电池的循环性能, 研究认为: $\mathrm{MnO}_{2}$ 与放电产物 $\mathrm{Li}_{2} \mathrm{O}$ 生成了 $\mathrm{Li}_{2} \mathrm{MnO}_{3}$, 充电时 $\mathrm{Li}_{2} \mathrm{MnO}_{3}$ 被分解成 $\mathrm{MnO}_{2}$ 和 $\mathrm{Li}_{2} \mathrm{O}$. 其循环性能的改善说明 $\mathrm{MnO}_{2}$ 的加入及 $\mathrm{Li}_{2} \mathrm{MnO}_{3}$ 的生成有利于电池充放电过程的进行.

(3)碳载 “金属/金属氧化物” 催化剂: 2011 年, 印地 安那大学与普渡大学印第安纳波利斯联合分校的 Sun 课 题组 ${ }^{[12]}$ 将 $\mathrm{Pd}$ 沉积在 $\beta-\mathrm{MnO}_{2}$ 棒表面, 制备了 $\mathrm{Pd} / \beta-\mathrm{MnO}_{2}$ 复合催化剂, 该催化剂的活性远高于单独使用 $\mathrm{Pd}$ 作为 催化剂的活性，而价格却低于纯 Pd 的价格.

2011 年, 日本九州大学 Thapa 课题组 ${ }^{[13]}$ 将介孔 $\alpha-\mathrm{MnO}_{2} / \mathrm{Pd}$ 用作催化剂, 首次放电比容量达到 545 $\mathrm{mAh} \cdot \mathrm{g}^{-1}$ (催化剂); 发现 $\mathrm{Pd}$ 在 $\mathrm{Li}_{2} \mathrm{O}_{2} / \mathrm{LiO}_{2}$ 还原为 $\mathrm{Li}$ 的过 程中表现了很好的催化活性, 使用 $\alpha-\mathrm{MnO}_{2}$ 时过电位为 $0.8 \mathrm{~V}$, 加入 $\mathrm{Pd}$ 后过电位降至 $0.6 \mathrm{~V}$, 充电电位降至 3.6 $\mathrm{V}$. 以电流密度为 0.25 和 $1.91 \mathrm{~mA} \cdot \mathrm{cm}^{-2}$ 恒流放电, 在 15 次循环之后放电比容量分别是 261(催化剂)和 212 $\mathrm{mAh} \cdot \mathrm{g}^{-1}$ (催化剂).

\section{1 .2 碳载体的微观结构与形貌的影响}

2007 年, 悉尼大学 Sun 课题组 ${ }^{[14]}$ 分别采用石墨烯纳 米片和 XC-72 碳粉制备空气阴极, 组装理-空气电池, 在相同的电流密度 $\left(0.1 \mathrm{~mA} \cdot \mathrm{cm}^{-2}\right)$ 进行恒流充放电测试. 结果表明: 采用 XC-72 碳粉时, 过电位为 $1.69 \mathrm{~V}$, 放电 比容量为 $1750 \mathrm{mAh} \cdot \mathrm{g}^{-1}$ (碳); 而石墨烯纳米片作阴极时, 过电位仅为 $1.22 \mathrm{~V}$, 比容量达到 $2750 \mathrm{mAh} \cdot \mathrm{g}^{-1}$ (碳). 这 说明不同的碳材料对氧气的还原催化作用有较大的影 响.

2009 年, 复旦大学余爱水课题组 ${ }^{[15]}$ 使用具有大孔 隙率的泡沫碳(MCF-C)作阴极, 放电比容量达到 2500 $\mathrm{mAh} \cdot \mathrm{g}^{-1}$ (用 Super-P 做阴极时比容量为 $1736 \mathrm{mAh} \cdot \mathrm{g}^{-1}$ ), 这为锂一空气电池的阴极选择方法提供了一种新的思路. 此外还对各种阴极材料的比容量、表面积和孔径等性质 作了对比(放电电流密度均为 $0.1 \mathrm{~mA} \cdot \mathrm{cm}^{-2}$ ), 如表 3 .

2010 年, 英国爱丁堡大学 Tra 等 ${ }^{[16]}$ 研究了一系列多 孔碳孔径的大小与电池性能之间的关系, 认为非水基电 解质锂一空气电池实用化障碍是阴极还原产物沉积引起 电极的钝化，并提出可将高比表面和大孔的碳材料用于 阴极，空气扩散电极的比容量和平均孔径之间有近似的 线性关系, 一定程度上随着孔径增大, 比容量也增大.

\section{1 .3 其他阴极材料}

2011 年, 中国科学院青岛生物能源与过程研究所 董杉木课题组 ${ }^{[17]}$ 将 $\mathrm{MoN}$ 均匀地涂在掺氮的石墨烯上 
表 3 一些阴极碳材料的比容量、表面积和孔径对比(放电电流密度为 $0.1 \mathrm{~mA} \cdot \mathrm{cm}^{-2}$ )

Table 3 Specific capacity $\left(0.1 \mathrm{~mA} \cdot \mathrm{cm}^{-2}\right)$, surface area and pore diameter of carbon materials

\begin{tabular}{lcccccccc}
\hline \multicolumn{1}{c}{ 样品 } & Super-P & XC-72 & 活性炭 & CNT & 石墨 & 石墨烯 & MCF-C & 球状石墨 \\
\hline 比容量 $/\left({\left.\mathrm{mAh} \cdot \mathrm{g}^{-1}\right)}^{1736}\right.$ & 762 & 414 & 583 & 560 & 2750 & 2500 & 1136 \\
表面积 $/\left(\mathrm{m}^{2} \cdot \mathrm{g}^{-1}\right)$ & 62 & 250 & 2100 & 40 & 6 & 2630 & 824 & 480 \\
孔径 $/ \mathrm{nm}$ & 50 & 2 & 2 & 10 & - & 100 & 30 & - \\
\hline
\end{tabular}

(MoN/NGS), 用于锂-空气电池的阴极, 放电电压为 3.1 $\mathrm{V}$, 放电电流密度为 $0.08 \mathrm{~mA} \cdot \mathrm{cm}^{-2}$ 时, 放电比容量为 $1050 \mathrm{mAh} \cdot \mathrm{g}^{-1}$ (碳十催化剂); 同样电流密度放电时, 没 有加入 $\mathrm{MoN}$ 时放电比容量仅有 $500 \mathrm{mAh} \cdot \mathrm{g}^{-1}$ (碳十催化 剂). 这些数据表明在纳米结构中加入 $\mathrm{MoN}$ 能够在一定 程度上提高锂-空气电池的放电比容量.

2011 年, 上海交通大学王红等 ${ }^{\left[{ }^{[18]}\right.}$ 用钴盐和锰盐与 含氮配体反应得到过渡金属配合物, 并用其与碳黑载体 复合制备了阴极. 实验结果表明: 电流密度为 0.05 $\mathrm{mA} \cdot \mathrm{cm}^{-2}$ 时, 首次放电比容量达到 $4870 \mathrm{mAh} \cdot \mathrm{g}^{-1}$, 放电 电压平台在 $2.8 \mathrm{~V}$ 左右. 该催化剂以廉价的含氮配体为 原料, 与贵金属、卟啉、酞菁等催化剂相比较, 具有制 备工艺更简单、重复性更好和成本更低等优点.

\section{2 电解质}

应用于锂-空气电池的电解质可分为四类: 水基电 解质、有机电解质、固体电解质、组合电解质.

\section{2 .1 水基电解质}

1976 年, Littauer 等 ${ }^{[19]}$ 首次发表了关于水基电解质 锂一空气电池的文章, 但后因无法有效控制金属锂和水 的化学反应而终止了研究.

2008 年, 日本三重大学的 Imanishi 课题组 ${ }^{[20,21]}$ 使用 无机固体电解质对阳极金属锂进行了保护, 设计的电池 结构分别为: $\operatorname{Li}|\operatorname{LISICON}| 1 \mathrm{~mol} \cdot \mathrm{L}^{-1} \operatorname{LiCl}(\mathrm{aq}) \mid \mathrm{Pt}$, 以及 Li-Al|LiPON|LATP|LiPON|Li-Al, 结果显示: LATP 在水 中有很高的稳定性, LiPON 薄膜可以有效地阻止 LATP 与 $\mathrm{Li}-\mathrm{Al}$ 合金的反应, 但电池的 “固/固” 界面阻抗过高, 室温阻抗高达 $8600 \Omega \cdot \mathrm{cm}^{2}$, 其应用受到限制.

同年, 日本三重大学 Zhang 等 ${ }^{[22]}$ 设计了水基锂-空 气电池, 结构为: $\mathrm{Li} / \mathrm{PEO}_{18} \mathrm{Li}\left(\mathrm{CF}_{3} \mathrm{SO}_{2}\right)_{2} \mathrm{~N} / \mathrm{LTAP} \mathrm{LiCl}(\mathrm{aq}) /$ $\mathrm{Pt}$, 其中 $\mathrm{LTAP}\left(\mathrm{Li}_{1+{ }^{+}+y} \mathrm{Ti}_{2-x} \mathrm{Al}_{x} \mathrm{P}_{3-y} \mathrm{Si}_{y} \mathrm{O}_{12}\right)$ 溶解于 $\mathrm{LiCl}$ 溶 液中作为电解质, 固体电解质 $\left[\mathrm{PEO}_{18} \mathrm{Li}\left(\mathrm{CF}_{3} \mathrm{SO}_{2}\right)_{2} \mathrm{~N}\right]$ 为隔 膜, 在 $60{ }^{\circ} \mathrm{C}$ 时电池阻抗为 $540 \Omega \cdot \mathrm{cm}^{2}$, 电池开路电压保 持在 $3.7 \mathrm{~V}$ 达到两个月的时间.

水基电解质的优点: 与有机电解质相比, 在锂 - 空 气电池中使用水基电解质的突出优点是: (1)放电产物为 $\mathrm{LiOH}$, 它溶解于水基电解质, 所以不会堵塞输氧通道; (2)与锂离子电池不同, 锂-空气电池是开放体系, 阴极 的输氧通道会造成电解质挥发, 而水基电解质的挥发性 远小于有机电解质, 有利于电解质的长时间工作; (3)其 开路电压高, 充放电过电位低、充放电效率高. 水基电 解质的缺点: 需采用无机固体电解质或高分子基固态电
解质对阳极金属锂进行保护，操作难度很大. 而且随 充、放电的进行，阳极金属锂与固态电解质之间容易产 生间隙，导致电池断路. 较理想的方法是使用含水基电 解质的组合电解质.

锂-空气电池放电时，阴极活性物质 “ $\mathrm{O}_{2}$ ” 从外侧通 过孔隙进入 “阴极/电解液” 界面, 部分 “ $\mathrm{O}_{2}$ ” 溶解在电 解液中, 室温时, 其在水基电解液中的溶解度约为 0.03 $\mathrm{cm}^{3} \mathrm{O}_{2} / \mathrm{cm}^{3}$, 而在有机电解质中的溶解度约为 $0.05 \sim 0.1$ $\mathrm{cm}^{3} \mathrm{O}_{2} / \mathrm{cm}^{3}$, 氧在界面得到电子被还原. 使用水基电解 质[图 2(A)]、放电时氧气得电子被还原生成 $\mathrm{OH}^{-}$, 与 $\mathrm{Li}^{+}$生成能溶于电解液的 $\mathrm{LiOH}$; 而使用非水基电解质时 [图 2(B)], 氧得电子还原后与 $\mathrm{Li}^{+}$生成不溶于电解液的 $\mathrm{Li}_{2} \mathrm{O}_{2}$ 和 $\mathrm{Li}_{2} \mathrm{O}$, 很容易堵塞多孔碳输氧通道.
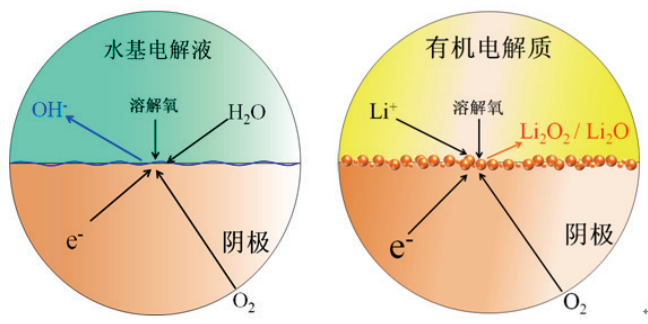

图 2 两相电解质反应示意图

Figure 2 Two phase systems in (A) aqueous electrolyte and (B) nonaqueous electrolyte

\subsection{2 非水基电解质}

(1)有机电解质: 1996年, Abraham 等 ${ }^{[23]}$ 设计的锂-空 气电池电解质为凝胶聚合物(PAN-PVDF)、有机溶剂为 碳酸乙烯酯(EC)和丙烯碳酸酯 $(\mathrm{PC}) 、$ 锂盐为 $\mathrm{LiPF}_{6}$, 开路 电压接近于 $3 \mathrm{~V}$, 实际放电电压为 $2.2 \sim 2.5 \mathrm{~V}$, 放电电流 密度不同时, 放电比容量为 $600 \sim 1410 \mathrm{mAh} \cdot \mathrm{g}^{-1}$, 具体 数值见表 4 .

表 4 放电电流密度不同时电池的比容量

Table 4 Discharge capacities of lithium air batteries at different current densities

\begin{tabular}{ccc}
\hline 电流密度 $/\left(\mathrm{mA} \cdot \mathrm{cm}^{-2}\right)$ & 放电电压 $/ \mathrm{V}$ & 比容量 $/\left(\mathrm{mAh} \cdot \mathrm{g}^{-1}\right)$ \\
\hline 0.10 & 2.5 & 1410 \\
0.25 & 2.4 & 1390 \\
0.50 & 2.3 & 800 \\
1.00 & 2.2 & 800 \\
2.00 & 2.2 & 600 \\
\hline
\end{tabular}

由表 4 中数据可以看出, 放电电压及放电比容量与 放电时的电流密度有关, 电流密度越高, 极化作用越强, 
放电平台越低, 放电比容量越小.

2002 年, 美国陆军实验室 $\operatorname{Read}^{[24]}$ 研究发现电解质 的组成对锂一空气电池性能和放电产物沉积行为影响很 大, 并认为: 电解质对于碳的润湿能力、阴极的厚度、 孔隙率和炭黑体积分数等性质对电池放比容量有影响. $\operatorname{Read}^{[25]}$ 使用乙醚电解质时, 电池放电性能稳定, 放电比 容量达到 $2800 \mathrm{mAh} \cdot \mathrm{g}^{-1}$. 实验结果表明, 当以大电流密 度 $\left(0.5 \mathrm{~mA} \cdot \mathrm{cm}^{-2}\right)$ 放电时, 放电比容量最主要受电解质 粘度的影响; 当小电流密度(如 0.2 或 $0.05 \mathrm{~mA} \cdot \mathrm{cm}^{-2}$ ) 放 电时, 比容量与电解质粘度的关系不大, 而且与电解质 的溶氧率以及阴极的电导率关系也都不大.

2010 年, 加利福尼亚罗伯特技术研究中心 Albertus 等 ${ }^{[26]}$ 在锂一空气电池中使用丙烯碳酸盐做为电解质, 通 过一系列实验后发现限制电池循环性能的主要是电池 内阻过大, 原因是有机电解质中阴极放电产物 $\left(\mathrm{Li}_{2} \mathrm{O}\right.$ 和 $\mathrm{Li}_{2} \mathrm{O}_{2}$ )均为电子的不良导体, 导致内阻的增加.

2011 年, 美国太平洋西北国家实验室 $\mathrm{Xu}$ 等 ${ }^{[8]}$ 使用 双 (三氟甲烷磺酰基)酰亚胺锂/PC/EC 做电解液与 $\mathrm{Li}_{2} \mathrm{O}_{2} /$ $\mathrm{Fe}_{3} \mathrm{O}_{4} /$ Super P 复合阴极材料、金属锂阳极匹配制备电池, 电池第一次充电至 $4.6 \mathrm{~V}$ 时, 发现释放的气体主要是 $\mathrm{O}_{2}$, 电池放电至 $2.0 \mathrm{~V}$, 当第二循环再充电至 $4.6 \mathrm{~V}$ 时, 发现 释放的气体主要是 $\mathrm{CO}_{2}$, 进一步分析证明放电产物中有 碳酸盐, 这可能是充电电压太高, 导致电解液分解所致.

表 $5^{[27]}$ 描述了电池比容量与有机电解液的组成及其 氧溶解度三者之间的关系, 从表中数据可以看出, 在电 解质中锂盐的浓度 $\left(1 \mathrm{~mol} \cdot \mathrm{L}^{-1}\right)$ 一定时 (表 5 , Nos. 1 6), 适当减小电解液的粘度有利于溶解氧浓度和电导率的 增加, 也有利于电池比容量的增加; 适当降低载流子浓 度时(表 5, Nos. 6, 7), 虽然使其电导率和粘度均有所降 低, 但由于其溶解氧增加, 其放电比容量也随之增加.

目前锂-空气电池的研究中应用较多的是有机电解 质. 与水基电解质相比, 有机电解质的主要优点是氧溶 解度高、对锂腐蚀小, 电池的制备相对简单, 可操作性 好. 其主要的缺点是: (1)放电产物为不溶于电解质的 $\mathrm{Li}_{2} \mathrm{O}$ 或 $\mathrm{Li}_{2} \mathrm{O}_{2}$, 形成沉淀堵塞输氧通道. (2)电解质易挥 发, 而电解质的补充操作不方便. (3) 2011 年, Bruce
等 ${ }^{[28]}$ 认为有机电解质的溶剂(例如 $\mathrm{PC}$ 或 $\mathrm{PC} / \mathrm{EC}$ )在电池 充电过程中容易产生不可逆的分解反应，认为真实的放 电过程是电解液的分解而并非氧气的还原, 并提出用价 格低，稳定性高的醚类有机电解质代替碳酸盐. 2012 年, Jung 等 ${ }^{[29]}$ 的研究表明, 醚类有机电解质在充电过程中 不发生分解, 适用于锂-空气电池. 另外, 使用有机电解 液时其放电产物主要是 $\mathrm{Li}_{2} \mathrm{O}_{2}$, 而 $\mathrm{Li}_{2} \mathrm{O}_{2}$ 是天然的 $\mathrm{CO}_{2}$ 吸附剂, 可直接与 $\mathrm{CO}_{2}$ 反应生成 $\mathrm{Li}_{2} \mathrm{CO}_{3}$. 因此, 目前基 于有机电解液的锂一氧电池阴极要用纯氧或氧/氮混合气 体为活性物质, 很难以含 $\mathrm{CO}_{2}$ 的空气为电极活性物质.

(2)疏水性离子液体: 2005 年，日本东芝公司 Kuboki 等 ${ }^{[30]}$ 研究了疏水离子液体电解质 EMITFSI(乙基-3-甲基 咪唑四氟硼酸盐)对于锂-空气电池放电性能的影响, 发 现 EMITFSI 不容易挥发, 且一定程度上阻止了阳极金 属锂与氧气直接接触、避免了副反应的发生, 放电比容 量达到了 $5360 \mathrm{mAh} \cdot \mathrm{g}^{-1}$ (碳).

2005 年, 武汉大学化学与分子科学学院冯金奎课 题组 ${ }^{[31]}$ 制备了一种应用于锂-空气电池中的季铵盐离子 液体(1-甲基-1-辛基哌啶三甲基磺酰亚胺 $\mathrm{PP}_{18} \mathrm{TFSI}$ )电解 质，实验表明：这种离子液体具有 $6 \mathrm{~V}$ 电化学窗口，还 具有很强的疏水性.

疏水离子液体的优点：热稳定性高、不挥发. 缺点 是: 黏度大、锂离子传导率偏低、做电解质使用时必须 要加入锂盐, 而锂盐会吸收水分, 同时会造成对金属锂 的腐蚀.

\subsection{3 组合电解质}

2009 年，日本能源技术研究所 Wang 课题组 ${ }^{[32]}$ 使用 组合电解质设计了锂-空气电池，在金属锂阳极一侧使 用有机电解液，在空气阴极一侧使用水基电解液，用固 体电解质将两极电解液分开, 且可以在两极间传输锂离 子. 电池以 $0.5 \mathrm{~mA} \cdot \mathrm{cm}^{-2}$ 的电流密度连续放电 $500 \mathrm{~h}$, 放 电比容量达到 $50000 \mathrm{mAh} \cdot \mathrm{g}^{-1}$ (碳十催化剂十粘结剂). 该课题组 ${ }^{[33]}$ 还设计了一种新型的锂-空气电池, 该电池 由能量转变单元和产物循环单元组成, 该电池可以长时 间的放电，放电电压达到了 $2.8 \mathrm{~V}$, 放电比容量达到

表 5 有机电解质中的氧溶解度 $a$ 、电导率 $\sigma$ 和粘度 $\eta$ 以及电池在不同电流密度时的比容量

Table 5 Composition of various nonaqueous electrolytes. Respective values for Bunsen solubility coefficient $a$, conductivity $\sigma$ and viscosity $\eta$ are compared with specific capacity at different current densities

\begin{tabular}{|c|c|c|c|c|c|c|c|c|}
\hline \multirow{2}{*}{ No. } & \multirow{2}{*}{ 有机电解质 } & \multirow{2}{*}{$\eta / \mathrm{cps}$} & \multirow{2}{*}{$a /\left(\mathrm{cm}^{3} \mathrm{O}_{2} \cdot \mathrm{cm}^{-3}\right)$} & \multirow{2}{*}{$\sigma /\left(\mathrm{mS} \cdot \mathrm{cm}^{-1}\right)$} & \multicolumn{4}{|c|}{ 不同电流密度 $/\left(\mathrm{mA} \cdot \mathrm{cm}^{-2}\right)$ 时放电比容量 $/\left(\mathrm{mAh} \cdot \mathrm{g}^{-1}\right)$} \\
\hline & & & & & 0.05 & 0.10 & 0.20 & 0.30 \\
\hline 1 & $1.0 \mathrm{~mol} \cdot \mathrm{L}^{-1} \mathrm{LiPF}_{6} \mathrm{PC}$ & 8.06 & 0.0516 & 5.5 & 648 & 380 & 203 & 129 \\
\hline 2 & $1.0 \mathrm{~mol} \cdot \mathrm{L}^{-1} \mathrm{LiPF}_{6} \mathrm{PC}: \mathrm{EC}(1: 1)$ & 7.73 & 0.0482 & 6.5 & 519 & 512 & 224 & 160 \\
\hline 3 & $1.0 \mathrm{~mol} \cdot \mathrm{L}^{-1} \operatorname{LiPF}_{6} \mathrm{PC}: \operatorname{DEC}(1: 1)$ & 4.78 & 0.0787 & 6.7 & 1881 & 1308 & 591 & 338 \\
\hline 4 & $1.0 \mathrm{~mol} \cdot \mathrm{L}^{-1} \mathrm{LiPF}_{6} \mathrm{PC}: \mathrm{DMC}(1: 1)$ & 3.50 & 0.0729 & 9.4 & 817 & 652 & 524 & 363 \\
\hline 5 & $1.0 \mathrm{~mol} \cdot \mathrm{L}^{-1} \operatorname{LiPF}_{6} \mathrm{PC}: \mathrm{DME}(1: 1)$ & 2.59 & 0.0722 & 13.2 & 1409 & 999 & 628 & 452 \\
\hline 6 & $1.0 \mathrm{~mol} \cdot \mathrm{L}^{-1} \operatorname{LiPF}_{6} \mathrm{PC}: \mathrm{DME}(1: 2)$ & 1.98 & 0.0998 & 15.9 & 1599 & 1095 & 678 & 518 \\
\hline 7 & $0.5 \mathrm{~mol} \cdot \mathrm{L}^{-1} \operatorname{LiPF}_{6} \mathrm{PC}:$ DME $(1: 2)$ & 1.19 & 0.1218 & 12.2 & 1650 & 1257 & 809 & 676 \\
\hline
\end{tabular}


$19000 \mathrm{mAh} \cdot \mathrm{g}^{-1}$ (碳十催化剂十粘结剂). 目前组合电解 质锂一空气电池仍处于初始研究阶段.

组合电解质的优点是: 空气阴极放电产物是易溶于 水基电解质的氢氧化锂, 输氧通道不易被堵塞; 而阳极 金属锂在有机电解质中得到了保护. 其关键问题是必须 要找合适的隔膜将两种电解液分开, 且能有效传导 $\mathrm{Li}^{+}$、 并阻止 $\mathrm{H}_{2} \mathrm{O}$ 与 $\mathrm{O}_{2}$ 进入阳极、对有机电解液和水相都有 良好的抗腐蚀性以及具一定的机械强度.

\section{2 .4 固体电解质}

2010 年, 美国代顿大学 Kumar 课题组 ${ }^{[34]}$ 设计了全 固态锂-空气电池, 其结构为: $\mathrm{Li} / \mathrm{PC} / \mathrm{LAGP} / \mathrm{PC} /$ 碳-GC; 其中, $\mathrm{PC}$ 是由 $\mathrm{PEO}, \mathrm{LiN}\left(\mathrm{SO}_{2} \mathrm{CF}_{2} \mathrm{CF}_{3}\right), \mathrm{Li}_{2} \mathrm{O}$ 和 $\mathrm{BN}$ 混合制 备而成的聚合物电解质; LAGP 指的是 $0.8 \mathrm{Li}_{2} \mathrm{O}$ $0.25 \mathrm{Al}_{2} \mathrm{O}_{3} \bullet 1.5 \mathrm{GeO}_{2} \cdot 1.5 \mathrm{P}_{2} \mathrm{O}_{5} ; \mathrm{GC}$ 是由高分散碳粉一聚合 物-玻璃粉组成，相关测试数据表明，电池在 $30 \sim 105$ ${ }^{\circ} \mathrm{C}$ 温度范围内电池表现出极好的热稳定性与可充性, 当 放电电流密度为 $0.05 \sim 0.25 \mathrm{~mA} \cdot \mathrm{cm}^{-2}$ 时, 电池可以顺利 进行 40 次充放电循环, 并且在充放电过程中极化电压 很小, 电池可逆性较好. 但其比容量非常低, 尤其在低 温时电池内部阻抗急剧增加, 导致电池放电性能更差.

固体电解质的优点: 可以增加电池的热稳定性、提 高工作温度, 有效防止金属锂被腐蚀. 缺点: 室温离子 导电性差、金属锂与固体电解质之间的界面阻抗很大, 而且随着充放电的进行固体电解质与金属锂之间容易 产生间隙，导致电池断路.

\section{3 其他影响因素}

\subsection{1 阴极空气疏水膜}

锂一空气电池理想条件应是在干燥的纯氧气条件下 进行有效地放电, 若由空气供氧时应对空气阴极做憎水 处理.

2010 年, 美国太平洋西北国家实验室 Zhang 等 ${ }^{[35]}$ 将硅油涂在阴极表面制成了一种空气疏水膜. 在相对湿 度为 $20 \% \sim 30 \%$ 时, 电池放电 $16.3 \mathrm{~d}$, 放电比容量为 789 $\mathrm{mAh} \cdot \mathrm{g}^{-1}$ (碳), 比能量为 $2182 \mathrm{Wh} \cdot \mathrm{kg}^{-1}$ (碳); 相比之下, 没有用硅油做疏水处理时电池放电时间仅为 $5.5 \mathrm{~d}$, 放 电比容量为 $267 \mathrm{mAh} \cdot \mathrm{g}^{-1}$ (碳), 比能量为 $704 \mathrm{Wh} \bullet \mathrm{kg}^{-1}$ (碳); 在相对湿度为 $20 \%$ 时, 阴极使用该疏水膜后放电 性能甚至高于电池在干燥环境(相对湿度 $<1 \%$, 不用疏 水膜)中的放电性能.

2011 年, 美国 Crowther 等 ${ }^{[36]}$ 合成了一种空气疏水 膜, 该膜是由聚四氟乙烯(PTFE)玻璃纤维组成的, 这种 膜可以有效地阻止空气中的水分腐蚀金属锂, 电池未使 用该膜时, 在放电电流密度为 $1 \mathrm{~mA} \cdot \mathrm{cm}^{-2}$ 的情况下, 放 电比容量为 $1500 \mathrm{mAh} \cdot \mathrm{g}^{-1}$ (碳); 在使用了该膜之后, 同 样的电流密度下, 放电比容量达到了 $6496 \mathrm{mAh} \cdot \mathrm{g}^{-1}$ (碳). 由此可见该疏水膜在锂-空气电池中有很广的应 用前景.
阴极疏水膜的作用是减少水分对疏水电解液性能 的影响及对金属锂阳极的腐蚀. 缺点：由于疏水膜在减 少水分进入电池的同时也可能减少了氧气的进入，造成 氧通量减少，导致其性能下降.

\subsection{2 放电深度}

2010 年, 复旦大学余爱水等 ${ }^{[37}$ 利用 $\alpha-\mathrm{MnO}_{2}$ 作为 锂-空气电池催化剂. 如图 3 首次放电比容量为 2300 $\mathrm{mAh} \cdot \mathrm{g}^{-1}$ (碳), 深度放电时, 循环 4 次后放电比容量仅有 $150 \mathrm{mAh} \cdot \mathrm{g}^{-1}$ (碳); 通过限制放电电压, 电池循环 10 次 后放电比容量仍高于 $1800 \mathrm{mAh} \cdot \mathrm{g}^{-1}$ (碳)、衰减很小. 实 验表明放电深度对电池的比容量和循环性能有很大影 响, 放电过深时阴极产物 $\mathrm{Li}_{2} \mathrm{O}_{2}$ 完全堵塞多孔碳孔道, 可能会导致电极膨胀，从而破坏电极材料的微观结构.

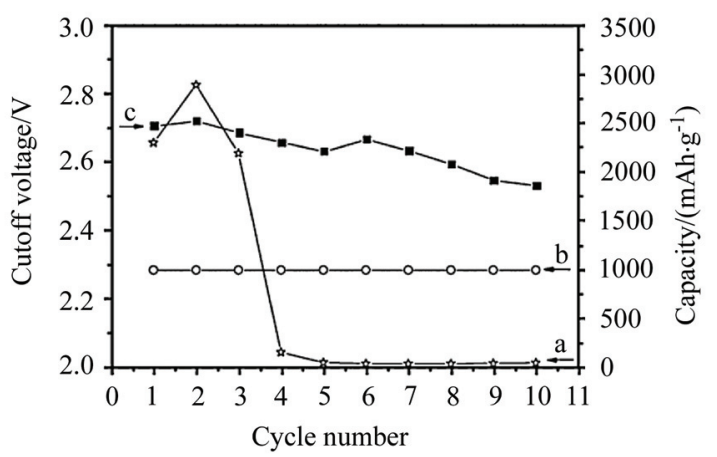

图 3 锂-空气电池的循环性能(a)深度放电, (b) 放电电流密度为 0.1 $\mathrm{mA} \cdot \mathrm{cm}^{-2}$, 控制放电深度在 $1000 \mathrm{mAh} \cdot \mathrm{g}^{-1}$, (c) 控制截止电压在 $2.5 \mathrm{~V}$ 的 放电曲线

Figure 3 Cycle performance of the lithium air battery with (a) deep discharge, (b) restricting capacity to $1000 \mathrm{mAh} \cdot \mathrm{g}^{-1}$ with a current density of $0.1 \mathrm{~mA} \cdot \mathrm{cm}^{-2}$, and (c) limited discharge depth with higher voltage cut-offs

\subsection{3 电池结构设计}

如图 1 所示，锂-空气电池有不同的结构设计，此外 电池组件的精细设计对电池的性能也有较大的影响.

2010 年印度科学院无机与物理化学研究中心 Eswaran 课题组 ${ }^{[38]}$ 设计的锂-空气电池阴极是由活化层 和扩散层组成的, 活化层是由碳、 $a-\mathrm{MnO}_{2}$ 和 PTFE 构成 的(质量比为 $90: 2.5: 7.5$ ), 扩散层是由多孔碳和 PTFE 构成的 (质量比为 $70: 30$ ). 当放电电流密度为 0.18 $\mathrm{mA} \cdot \mathrm{cm}^{-2}$ 时, 放电比容量达到 $3100 \mathrm{mAh} \cdot \mathrm{g}^{-1}$, 实验表明 这种结构的锂一空气电池有很广的应用前景.

2012 年德克萨斯大学奥斯汀分校 $\mathrm{Li}$ 等 ${ }^{[39]}$ 设计了一 种使用组合电解质的锂-空气电池, 其结构为 $\mathrm{Li} \mid 1 \mathrm{~mol} \cdot$ $\mathrm{L}^{-1} \mathrm{LiPF}_{6}|\mathrm{LTAP}| 0.1 \mathrm{~mol} \cdot \mathrm{L}^{-1} \quad \mathrm{H}_{3} \mathrm{PO}_{4}+1 \mathrm{~mol} \cdot \mathrm{L}^{-1}$ $\mathrm{LiH}_{2} \mathrm{PO}_{4} \mid \mathrm{Pt}$. 电池中金属锂作阳极，空气阴极置于磷酸 盐缓冲液中(缓冲液可以提高平均放电电压, 减缓电解 液 $\mathrm{pH}$ 值上升的速度)，使用 LTAP 膜将水基电解质和非 水基电解质分隔开，阴极用 Pt 作催化剂，阳极用网状泡 沫镍作集流体. 放电电流密度为 $0.5 \mathrm{~mA} \cdot \mathrm{cm}^{-2}$ 时, 充放 电循环 20 次之后, 放电比容量为 $221 \mathrm{mAh}^{-1} \mathrm{~g}^{-1}$, 比能量 


\section{为 $770 \mathrm{Wh} \cdot \mathrm{kg}^{-1}$.}

\section{4 理论研究}

2007 年, 美国代顿大学化学系 Sandhu 等 ${ }^{[40]}$ 对锂空气电池做了理论研究, 用 Mathematica 软件模拟的电 池放电曲线和实际的放电曲线非常相似, 并研究了电池 的放电电流密度、氧分压、孔隙率对于电池放电比容量 的影响. 模拟结果表明: 电池的比容量随电流密度的增 加而减小、随氧分压的增加而增加, 而材料孔隙率太大 或太小都会减小电池放电比容量, 氧浓度的增加会缩短 电池放电时间，阴极厚度减小会明显增加放电比容量.

2009 年美国东北大学 Laoire 等 ${ }^{[41]}$ 通过实验研究认 为阴极反应机理如下: $\mathrm{Li}^{+}$在阴极与 $\mathrm{O}_{2}$ 首先形成超氧化 物 $\mathrm{LiO}_{2}, \mathrm{LiO}_{2}$ 再接受电子与 $\mathrm{Li}^{+}$反应生成 $\mathrm{Li}_{2} \mathrm{O}_{2}$, 或 $\mathrm{LiO}_{2}$ 自身分解为 $\mathrm{Li}_{2} \mathrm{O}_{2}$, 但是 $\mathrm{Li}_{2} \mathrm{O}_{2}$ 不稳定最后分解为 $\mathrm{Li}^{+}$和 $\mathrm{O}_{2}$ ，其半反应如下:

$$
\begin{aligned}
& \mathrm{O}_{2}+\mathrm{e}^{-}+\mathrm{Li}^{+} \rightarrow \mathrm{LiO}_{2} \\
& \mathrm{LiO}_{2}+\mathrm{e}^{-}+\mathrm{Li}^{+} \rightarrow \mathrm{Li}_{2} \mathrm{O}_{2} \\
& \mathrm{LiO}_{2} \rightarrow \mathrm{Li}_{2} \mathrm{O}_{2}+\mathrm{O}_{2} \\
& \mathrm{Li}_{2} \mathrm{O}_{2} \rightarrow \mathrm{O}_{2}+\mathrm{e}^{-}+\mathrm{Li}^{+}
\end{aligned}
$$

2010 年, 美国橡树岭国家实验室 Xu 课题组 ${ }^{[42]}$ 用密 度泛函理论和热力学方法模拟研究了 $\mathrm{Li}$ 与 $\mathrm{O}_{2}$ 在催化剂 $\mathrm{Au}$ 和 $\mathrm{Pt}$ 表面的氧化还原反应, 发现在 $\mathrm{Au}$ 表面 Li2O2 分解产生 $\mathrm{O}_{2}$, 其可逆反应电位为 $1.51 \mathrm{~V}$; 在干净的金属 $\mathrm{Pt}$ 表面吸附 $\mathrm{O}_{2}$ 的速率非常慢, $\mathrm{O}_{2}$ 的可逆还原电位为 1.97 V. 并认为在两种金属表面进行的反应都削弱了 $\mathrm{O}-\mathrm{O}$ 键能, 所以放电产物主要是氧化锂 $\mathrm{Li}_{2} \mathrm{O}$, 而不是过氧化 锂 $\mathrm{Li}_{2} \mathrm{O}_{2}$.

2010 年, 丹麦科技大学 Hummelshøj 等 ${ }^{[43]}$ 同样用密 度泛函理论估算了锂-空气电池充放电过程中形成中间 体时的自由能, 给出了自由能图, 分析了产生过电位的 原因, 认为 $\mathrm{Li}$ 空穴可以使 $\mathrm{Li}_{2} \mathrm{O}_{2}$ 成为导体, 其半反应式 如 Eqs. 13, 14.

$$
\begin{aligned}
& \mathrm{O}_{2}+\mathrm{e}^{-}+\mathrm{Li}^{+}+* \rightarrow \mathrm{LiO}_{2}^{*} \\
& \mathrm{Li}^{+}+\mathrm{e}^{-}+\mathrm{LiO}_{2}^{*} \rightarrow \mathrm{Li}_{2} \mathrm{O}_{2}
\end{aligned}
$$

其中*表示 $\mathrm{Li}_{2} \mathrm{O}_{2}$ 表面放电产物生长的区域, $\mathrm{LiO}_{2}^{*}$ 为锂 空位.

2011 年, 丹麦科技大学 Chen 等 ${ }^{[44]}$ 用密度泛函理论 和非平衡格林函数进行计算, 认为电子传输可通过阴极 放电产物 $\mathrm{Li}_{2} \mathrm{O}_{2}$ 进行, 在用 $\mathrm{Au}$ 和 $\mathrm{Pt}$ 作催化剂时, 其电子 传输取决于绝缘体及金属界面的取向和晶格的匹配, 而 且发现金属锂中有空位, 在充电条件下空位发生移动.

\section{5 锂一空气电池表征分析方法}

利用电池性能测试仪对锂-空气电池进行循环伏 安、交流阻抗、充放电比容量、充放电循环性能测试以 外, 在其反应前、后以及反应过程对电极材料、隔膜、
电解液以及电池反应产物的表征、分析方法大致如下: (1) X 射线衍射光谱(XRD)用于表征材料的微观组成和 微观结构, 尤其可以表征电池反应以及副反应的产物 (例如 $\mathrm{Li}_{2} \mathrm{O}, \mathrm{Li}_{2} \mathrm{O}_{2}, \mathrm{Li}_{2} \mathrm{CO}_{3}$ 等). (2)扫描电镜和透射电镜 (SEM and TEM)用于表征电极材料等的微观形貌. (3)红 外光谱(FTIR)和表面增强拉曼光谱(SERS)用于表征在 反应前后电极材料、电解质内包含的化学键类型, 进而 确定其组成, 尤其可以确定有机化合物分解后产物的构 成 ${ }^{[29]}$. (4)核磁共振(NMR)用于分析有机电解液的组成及 结构, 特别可用于确定有机电解液在电池的充、放电过 程中是否发生了分解并确定分解产物 ${ }^{[28]}$. (5)微分电化学 质谱(DEMS) 可现场检测电化学反应中的挥发气体 $\left(\mathrm{H}_{2} \mathrm{O}\right.$, $\mathrm{CO}_{2}, \mathrm{H}_{2}$ 等 $)^{[28]}$. (6) 飞行一时间二次离子质谱(TOF-SIMS) 用于捕捉、分析充放电过程中的中间产物 ${ }^{[29]}$. (7)动电位 循环一恒电流加速分析(PCGA) 用于分析电池中电解液 的电极过程, 分析电池的比容量随电池电动势的变化关 系、电池的比容量的增量随电池电动势的变化关系 ${ }^{[29]}$.

\section{6 结束语}

锂一空气电池具有诸多的优点, 是一种环境友好的 新型电池体系，既可以做二次电池，也可以做一次燃料 电池, 但其基础性研究还不够充分, 实用化的障碍还没 有攻破, 在成为商用电池之前还有一系列的问题需要解 决. 若能: (1)提高阴极催化剂的效率和稳定性、大幅降 低过电位; (2)在保证电导率要求的前提下，降低非水基 电解液的粘度以增加其溶氧量、降低其挥发性; (3)制备 满足组合电解质应用的固体电解质隔膜等, 其实用化进 程会大大加快，应用领域将非常广阔.

\section{作者简介}

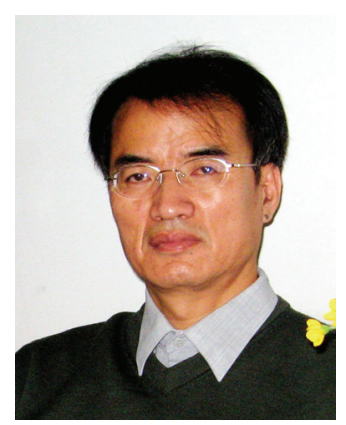

顾大明, 1956 年出生, 博士, 哈尔滨工业大学理学院教 授, 博士生导师. 1982 年在哈尔滨建筑工程学院获学士学位, 1989 年在哈尔滨建筑工程学院获硕士学位, 2005 年在哈尔滨 工业大学获博士学位. 2005 年任职教授, 2007 年任职博士生导 师. 分别在Advanced Material, Energy \& Environmental Science, Chem. Commun., Applied Catalysis B: Environmental, Journal of Power Sources, Journal of Colloid and Interface Science 等期刊 发表学术论文 40 余篇, 主要研究领域为锂空气电池、锂离子 电池、燃料电池等. 
张传明, 男, 1988 年出生, 哈尔滨工业大学理学院硕士生, 研究方向: 锂空气电池.

顾硕, 男, 1984 年出生, 美国乔治华盛顿大学博士生, 研 究方向: 磁制冷材料.

张音, 女, 1986 年出生, 哈尔滨工业大学理学院博士生, 研究方向: 锂空气电池.

王余, 女, 1989 年出生, 哈尔滨工业大学理学院硕士生, 研究方向: 锂空气电池.

强亮生, 男, 1954 年出生, 哈尔滨工业大学理学院教授, 博士生导师, 研究方向: 晶体材料、纳米材料.

\section{References}

[1] Kowalczk, I.; Read, J.; Salomon, M. Pure Appl. Chem. 2007, 79, 851.

[2] Lu, Y. C.; Gasteiger, H. A.; Parent, M. C.; Chiloyan, V.; Yang, S. H. Electrochem. Solid-State Lett. 2010, 13, A69.

[3] Lu, Y. C.; Xu, Z. C.; Gasteiger, H. A.; Chen, S.; Kimberly, H. S.; Yang, S. H. J. Am. Chem. Soc. 2010, 132, 12170.

[4] Ogasawara, T.; Débart, A.; Holzapfel, M.; Novák, P.; Bruce, P. G. J. Am. Chem. Soc. 2006, 128, 1390.

[5] Débart, A.; Bao, J. L.; Armstrong, G.; Bruce, P. G. J. Power Sources 2007, 174, 1177.

[6] Débart, A.; Paterson, A. J.; Bao, J.-L.; Bruce, P. G. Angew. Chem., Int. Ed. 2008, 47, 4521.

[7] Crisostomo, V. M. B.; Ngala, J. K.; Alia, S.; Dobley, A.; Morein, C.; Chen, C. H.; Shen, X. F.; Suib, S. L. Chem. Mater. 2007, 19, 1832.

[8] Xu, W.; Viswanathan, V. V.; Wang, D.-Y.; Towne, S. A.; Xiao, J.; Nie, Z. M.; Hu, D. H.; Zhang, J. G. J. Power Sources 2011, 196, 3894.

[9] Xiao, J.; Xu, W.; Wang, D. Y.; Zhang, J. G. J. Electrochem. Soc. 2010, 157, A294.

[10] Cheng, H.; Scott, K. J. Power Sources 2010, 195, 1370.

[11] Zhang, G. Q.; Zheng, J. P. Liang, R.; Zhang, C.; Wang, B.; Au, M.; Hendrickson, M.; Plichta, E. J. J. Electrochem. Soc. 2011, 158, A822.

[12] Sun, W.; Hsu, A.; Chen, R. R. J. Power Sources 2011, 196, 4491.

[13] Thapa, A. K.; Ishihara, T. J. Power Sources 2011, 196, 7016.

[14] Sun, B.; Wang, B.; Su, D. W. Carbon 2012, 50, 727.

[15] Yang, X. H.; He, P.; Xia, Y. Y. Electrochem. Commun. 2009, 11, 1127.

[16] Tra, C.; Yang, X, Q.; Qu, D. Y. J. Power Sources 2010, 195, 2057.

[17] Dong, S. M.; Chen, X.; Zhang, K. J.; Gu, L.; Zhang, L. X.; Zhou, X. H.; Li, L. F.; Liu, Z. H.; Han, P. X.; Xu, H. X.; Yao, J. H.; Zhang, G. J.; Zhang, X. Y.; Shang, C. J.; Cui, G. L.; Chen, L. Q. Chem. Commun. 2011, 47, 11291.

[18] Wang, H.; Liao, X. Z.; Ma, Z. F. CN 201110131455, 2011 [Chem. Abstr. 2011, 102240574].
[19] Littauer, E. L.; Tsai, K. C. J. Electrochem. Soc. 1976, 2, 163.

[20] Imanishi, N.; Hasegawa, S.; Zhang, T.; Hirano, A.; Takeda, Y.; Yamamoto, O. J. Power Sources 2008, 185, 1392.

[21] Hasegawa, S.; Imanishi, N.; Zhang, T.; Xie, J.; Hirano, A.; Takeda, Y.; Yamamoto, O. J. Power Sources 2009, 189, 371.

[22] Zhang, T.; Imanishi, N.; Hasegawa, S.; Hirano, A.; Xie, J.; Takeda, Y.; Yamamoto, O. Sammes, N. J. Electrochem. Soc. 2008, 155, A965.

[23] Abraham, K. M.; Jiang, Z. J. Electrochem. Soc. 1996, 143, 1.

[24] Read, J. J. Electrochem. Soc. 2002, 149, A1190.

[25] Read, J. J. Electrochem. Soc. 2006, 153, A96.

[26] Albertus, P.; Girishkumar, G.; McCloskey, B.; Roel, S. S.-C.; Kozinsky, B.; Christensen, J.; Luntz, A. C. J. Electrochem. Soc. 2011, 158, A343.

[27] Read, J.; Mutolo, K.; Ervin, M.; Behl, W.; Wolfenstine, J.; Driedger, A.; Foster, D. J. Electrochem. Soc. 2003, 150, A1351.

[28] Freunberger, S. A.; Chen, Y. H.; Peng, Z. Q.; Griffin, J. M.; Hardwick, L. J.; Bard, F.; Nov, P.; Bruce, P. G. J. Am. Chem. Soc. 2011, 133, 766 .

[29] Jung, H. G.; Hassoun, J.; Park, J. B.; Sun, Y. K.; Scrosati, B. Nat. Chem. 2012, 4, 579.

[30] Kuboki, T.; Okuyama, T.; Ohsaki, T.; Takami, N. J. Power Sources 2005, 146, 766 .

[31] Feng, J. K.; Cao, Y. L.; Zhou, W. C. Thirteenth National Electrochemical Meeting, Guangzhou, 2005, pp. 110 111. (冯金奎, 曹余良, 周文超, 第十三次全国电化学会议论文, 广州, 2005, pp. $110 \sim 111$.)

[32] Wang, Y. G.; Zhou, H. S. J. Power Sources 2010, 195, 358.

[33] He, P.; Wang, Y. G.; Zhou, H. S. Electrochem. Commun. 2010, 12, 1686.

[34] Kichambare, P.; Kumar, J.; Rodrigues, S.; Kumar, B. J. Power Sources 2011, 196, 3310

[35] Zhang, J.; Xu, W.; Liu, W. J. Power Sources 2010, 195, 7438.

[36] Crowther, O.; Keenya, D.; Moureaua, D. M.; Meyer, B.; Salomon, M.; Hendrickson, M. J. Power Sources 2012, 202, 347.

[37] Zhang, D.; Fu, Z. H.; Wei, Z.; Huang, T.; Yu, A. S. J. Electrochem. Soc. 2010, 157, A362.

[38] Eswaran, M.; Munichandraiah, N.; Scanlonb, L. G. Electrochem. Solid-State Lett. 2010, 13, A121.

[39] Li, L. J.; Zhao, X. S.; Manthiram, A. Electrochem. Commun. 2012, $14,78$.

[40] Sandhu, S. S.; Fellner, J. P.; Brutchen, G. W. J. Power Sources 2007, 164,365 .

[41] Laoire, C. O.; Mukerjee, S.; Abraham, K. M.; Plichta, E. J.; Hendrickson, M. A. J. Phys. Chem. C 2009, 113, 20127.

[42] Xu, Y.; Shelton, W. A. J. Chem. Phys. 2010, 133, 024703.

[43] Hummelshøj, J. S.; Blomqvist, J.; Datta, S.; Vegge, T.; Rossmeisi, J.; Thygesen, K. S.; Luntz, A. C.; Jacobsen, K. W.; Nørskov, J. K. J. Chem. Phys. 2010, 132, 071101.

[44] Chen, J. Z.; Hummelshøj, J. S.; Thygesen, K. S.; Myrdal, J. S. G.; Nørskov, J. K.; Vegge, T. Catal. Today 2011, 165, 2. 